\title{
An investigation into the classroom talk of Iranian EFL novice vs. experienced teachers
}

\section{Amir Ghajarieh}

Department of Language Teaching and Translation, University of Ershad-Damavand

Author's email ghajarieh.amir@e-damavandihe.ac.ir

\section{Nastaran Jalali}

Department of Language Teaching and Translation, University of Ershad-Damavand

Author's email Nastaranjalali.71@gmail.com

\section{Mohammad-Amin Mozaheb*}

Department of Foreign Languages

Language Center, Imam Sadiq University

Author's email mozaheb.ma@gmail.com

DOI: https://doi.org/10.18326/rgt.v12i2.100-125

Corresponding Author*

\section{Submission Track:}

Received: 29-09-2019

Final Revision: 20-11-2019

Available online: 01-12-2019

\begin{abstract}
This study investigates the classroom talk of Iranian EFL novice versus experienced teachers with emphasis on the quality of communicative features through a linguistic lens provided by the SETT (Self-Evaluation of Teacher Talk) framework and TTFS (Teacher Talk Functional Scale) checklist. In so doing, 10 intermediate-level classrooms running by five novice and five experienced teachers were observed, each case twice. Eight distinctive
\end{abstract}


communicative features of TT emerged upon the initial analysis of database obtained from the audio-recordings of 20 class sessions, totaling 30 hours of naturally generated input. Subsequently, the audio-recorded materials were carefully transcribed and analyzed in correspondence with the observation data in an attempt to compare how novice and experienced teachers present their talk. The results indicated both novice and experienced teachers enact communicative aspects of classroom talk; however, the quality of presentation in the case of the experienced group was far better. This in turn highlights the importance of raising awareness regarding TT features in teacher training courses. New communicative aspects of teacher talk highlighted in this study, including the use of L1 and language gradation, would help define new research paths exploring the classroom discourse. Further research inspired by this study needs to explore other aspects of teacher-student interactions in various educational settings.

Keywords: classroom talk, teacher talk, discourse, novice teachers, teacher education

\section{INTRODUCTION}

Teacher talk investigation in the context of language learning classrooms has been the focal point of a fair number of studies over the past recent years. However, such element of the classroom discourse still appears to be far from being fully understood and the teachers' role in EFL classroom context may need to be reconsidered (Rahmani Doqaruni, 2017). According to Walsh (2002), teachers have been mostly criticized over their excessive TTT (Teacher Talking Time). Additionally, in-service and pre-service courses have suggested teachers to reduce their talking time. Thus, the focus was on quantity rather than quality of how teachers communicate in the classroom. As he mentioned (2002, p.4), this has to be otherwise; that is "the focus should be on quality rather than quantity by recognizing the relationship between language use and pedagogic purpose". 
Upon addressing the dominance of teaching methods as the only route to successful language learning, research into the communicative features of language teaching in the post-method era has gain prominence in recent decades. Prior to such a turning point and paradigm shift in the language teaching disciple, the underlying assumption in language teaching predominantly revolved around how one could find the "right method". For instance, Scherer and Wertheimer (1964) investigated the comparative effectiveness of various methods such as grammar translation, audioLingualism, and cognitive code, but they could not pin down which methodology had more priority over others (Ellis, 1985, p.143, 2015).

Despite the outward differences of these language teaching methods in their basic principles, they led to very similar patterns of classroom communication and their plausible language learning outcomes were to a great extent similar to one another. Emphasizing method as the basic principle was revisited by researchers in language learning and practical teaching line of research given that they began to make the assumption that the major variable affecting SLA (Second Language Acquisition) was the classroom interaction. As Ellis $(1985,2015)$ mentioned, "an offshoot of the comparative method studies, then, was to direct researchers' attention to the process of classroom interaction by collecting language data from the classroom itself". Further, he contended the classroom process has different forms; namely, interaction analysis, teacher talk and discourse analysis. In terms of his assumptions, all classroom processes, including giving instructions, asking questions, providing feedback, are in close contact with teacher talk and hence, an important part of classroom research. 
According to Aisyah (2016, p.64), "teacher talk is a big influence on students' understanding and acquisition of a language. Students can learn a lot from the talk that the teacher gives, both in first and foreign language."

\section{Teacher talk in communicative framework of post-method era}

With the demise of method in language teaching, as Stern notes, "several developments indicate a shift in language pedagogy away from the single method concept as the main approach to language teaching" (1983, p. 477). Teachers and students as the main players in classroom interaction took the center stage in the post method era with research into communicative aspects of classroom interaction gaining prominence in recent decades (e.g. see Incecay, 2010; Sert, 2013). No one can deny the role of teachers in constructing and leading the classroom interaction, particular their active participation in any talk around the text and classroom discussions. While in the post method era, teachers' cognitions and perceptions concerning language teaching have been investigated in quite a number of studies, various aspects of their performance in class and the discourses produced in interactions with students would appear to require further detailed analysis due to the humanistic nature of teaching and training that influence the mind and behavior of language learners in the classroom context.

Teaching process and classroom interaction without examining teachers' behavior--in particular the characteristics of teacher talk--is incomplete. Teacher talk is what every learner can intrinsically benefit from the moment he/she steps in class. The quality of such medium in an educational setting would arguably be influential in the case of the learners as many of whom consider the teacher as a trustable source of language knowledge and frame of reference in debates and issue brought up in class. A growing number 
of studies, including Tsui, (2003) and Akbari and Tajik (2012), have investigated experienced and novice teachers' talk in the literature. However, previous studies on teacher talk were mostly focused on experienced teachers (Asik \& Gonen, 2016) with just a few aimed at highlighting the crucial factor in in-experienced EFL teachers (e.g. Rahmani Doqaruni, 2017). Additionally, few (if any) of these studies analyzed the teacher talk through the linguistics lens with emphasis on both teachers' cognition and behavior. As such teacher talk should be studied in detail to identify how various factors, including experience, can affect teacher performance in an EFL context.

\section{Teacher talk categories}

Many researchers focus on various features of teacher talk classified into different categories. For instance, in 1970 Flander developed a system of interaction analysis (FIAC) with emphasis on how teacher talk can be viewed in seven categories and two sub-categories of indirect influence as well as direct influence. Indirect influence embodies accepting feeling, appraisal, accepting students' ideas and asking questions. Direct influence is divided into giving directions and lectures as well as criticizing authority.

Each of these categories has different functions and affects students. Hence, using the right portion of these categories would lead to an effective teaching and learning process (Aisyah, 2016). A while after Flanders' (1970) study, Maskowitz (1971) developed 'Flint' system standing for the foreign language interaction system that encompasses all of the categories in the Flanders' classification along with a number of other dimensions. She developed the new model to describe another interaction analysis instrument 
for the foreign language classroom and to assess nonverbal communications as well as the quantity of student and teacher talk in the target language. Describing her model, she emphasized nonverbal behavior adopted by the teacher. For instance, when the teacher without saying a word calls on students by merely pointing at them or using the head nodding to have them speak. It can be asserted that this is the main difference comparing Flint model with FIAC model.

Walsh's (2006a) SETT framework is founded upon social constructivist theory has roots in conversation analysis with the SETT standing for Self-Evaluation of Teacher Talk. The model used in the analysis of classroom discourse mainly focuses on teacher-fronted classrooms, highlighting the relationship between teacher talk quality and learners' contribution in an EFL context. Additionally, it suggests that a relationship exists between teacher talk and pedagogic purposes.

Walsh (2006a) holds the classroom context cannot stand in isolation and that context is shaped by participants and through interactions with pedagogic objectives. The term 'mode' (Walsh, 2006b, p.62) is defined as an L2 classroom micro context which has pedagogic goals and interactional features determined by the teachers' use of language. Walsh's model provides a descriptive system which teachers can apply to understand interactional processes in their own classrooms. The SETT framework (Walsh, 2006a, p.140) is identified by four patterns of modes; namely, "managerial mode, material mode, classroom context mode and skill and system mode."

A thin number of Iranian researchers such as (Poorebrahim, et al., 2015; Shamsipour \& Allami, 2012), divided teacher talk features in two categories of constructive (encouraging) and obstructive (interfering). According to their investigations constructive features of teacher talk based on observations and 
visual-recordings contain confirmation check, scaffolding, direct error correction, content feedback, extended wait-time, referential questions and display questions. Obstructive features also encompass the areas of teacher echo, teacher interruption and turn completion (Poorebrahim et al., 2015).

English Language Teacher Talk Functional Scale (TTFS) was another model developed and validated by Iranian researchers (Khany \& Malmir, 2017). The scale is aimed at developing a teacher talk analysis tool whose items are confined to the ELT (English Language Teaching) classroom for "lack of an existing assessment tool" (p. 39). One of the advantages of their scale over other similar models is that it can be used for classroom interactions which are not necessarily led by teachers (see appendix A and appendix B representing TTFS developed by Khany and Malmir (2017) founded on major components of TT from the literature).

A growing body of literature on the classroom discourse with a focus on novice and experienced teachers has been carried out (e.g. Doganay \& Ozturk, 2011; Fereitas, Jimenez \& Mellado, 2004; Melnick \& Meister, 2008; Rahmani Doqaruni 2017). One of these recent studies, Rahmani Doqaruni (2017), compared novice and experienced teachers to scrutinize emerging communicative features in their talk. He utilized audio-recorded materials and semi-structured interviews, with the findings suggesting that the classroom behavior of experienced teachers is more stable and less variable. Furthermore, the study noted that due to the confrontation of experienced teachers with different teaching contexts, they have become more aware of the details that can affect their performance as a teacher. 


\section{RESEARCH QUESTIONS}

With regard to the importance of intersection between teacher talk and teacher training course for pre- and in-service teachers, this study is an attempt to investigate distinctive communicative features of teacher talk through a linguistic lens provided by the SETT framework and TTFS checklist with the teaching experience focused as the potential influencing variable. For the purposes of this study, the following research questions have been adopted:

1. What are the distinctive communicative features of an experienced teacher versus a novice teacher based on recurring patterns of teacher talk?

2. How such distinctive communicative features can affect the quality of teacher talk in terms of experience?

\section{RESEARCH METHOD}

In this study, ten teachers hired at Safir English Institute, located in Iranian capital city of Tehran were selected as the study cases for further investigation and exploration in the classroom talk research area. Prior to their recruitment at Safir Institute, all teacher cases had attended and passed preservice training courses. It is also worth noting that they taught intermediatelevel English courses and were categorized as novice and experienced teachers.

Upon examine the related studies, in the case of teacher education, experienced teachers had at least four to five years of experience (e.g., Gatbonton, 1999; Tsui, 2003) and were coded as ET1, ET2, ET3, ET4 and ET5 in the present study. Novice teachers were those who had just completed their training or they had less than four years of experience. This group of teachers was coded as NT1, NT2, NT3, NT4 and NT5. All teachers were female with 
five of whom having related educational background holding a Bachelor's and/or Master's in English Language Teaching. Teachers were not fully aware that one of the researchers intended to examine distinctive communicative features of experienced versus novice teachers and were simply informed that the study aimed to investigate their talk.

A further note on the cases of this study is that ET1, ET2, ET3, ET4 and ET5 possessed teaching experience of over ten, seven, nine, ten and six years of experience, respectively. Whereas NT1-NT5 had the teaching experience ranging from one to three years. Ten intact EFL classes were chosen for this study, each consists an average of ten students signing up for intermediate level English courses. All the classrooms were equipped with high quality video cameras. When need be, one of the authors checked the videos. While the main instrumentations in this study were audio recorded material and the observation, one of the authors made use of a checklist developed by Khany and Malmir (2017) to further validate the observation data. Moreover, an interview was conducted with a supervisor at Safir Institute regarding preservice courses organized by the managing board at the language teaching center.

\section{Instruments and procedure}

This study rests upon a corpus obtained from observation of twenty class sessions run by novice and experienced teachers with the number of session being a "reasonable sample size" in a wide array of similar studies. One of the authors observed ten classes each of them twice, with five+five running by novice and experienced teachers. Additionally, in term of data collection procedure, this study took the following measures. Initially, each classroom 
was observed twice by a validated checklist developed by Khany and Malmir (2017) (See appendix A\& B) with each session lasting for 90 minutes.

Additionally, a voice recorder was placed near each teacher in order to record the teacher's voice clearly and capture the classroom interaction. All classes at Safir Institute are equipped with video cameras capturing high quality visual data. The researchers accessed such data in case of more clarification. Nevertheless, the major portion of data was gathered through audio recorded materials alongside observations. As mentioned earlier, this study is a case study and "one of the advantages is its unobstructiveness; the presence of the observer does not influence what is being observed" (Ary et al., 2014, p. 489). The observer did not interrupt the flow of communication occurring in each observed class, instead she silently auditing classrooms while taking notes if need be.

First step taken towards finding answers of research questions was to analyze audio recorded materials and results obtained from each observed classroom. By so doing, data in its entirety were transcribed followed by identification of distinctive communicative features that emerged in novice and experienced teachers' talk. Distinctive communicative features were analyzed and categorized based on the SETT (Self-evaluation of Teacher Talk) framework (Walsh, 2006a).

\section{RESULTS \& DISCUSSION}

The first research question adopted in this study deals with the distinctive communicative features of experienced versus a novice teacher based on recurring patterns of TT. The SETT framework (self-evaluation of 
teacher talk) developed by Walsh (2006a), was adopted for the purposes of this study.

The SETT is a comprehensive framework aimed at evaluating the interface between language in use and its possible pedagogic purpose in a classroom micro-context called 'mode' (Walsh, 2006a). Different teacher talk features were developed by Walsh among which 6 features were chosen to fit the obtained data in this study based on the preliminary analysis of recurring themes in teacher talk.

Different types of communicative features were coded into one of the following patterns:

1. Display questions

2. Referential questions

3. Direct and indirect repair

4. Negotiation of meaning through clarification request and repetition

5. Content and form-focused feedback

6. Extended wait time

7. Language grading

8. Teachers use of first language

This typology was developed based on SETT and TTFS, with this study further analyzing some other features as contributions to these models. Two of the authors acted as the raters of the coded data, and the high index for interrater reliability for the two was established (.90) using Cohen's Kappa. It is also notable that in seeking to ensure the raters have not imposed any ideology based on coded categories, thematic analysis was used to identify recurring themes emerging from the data. 
Table 1. Coded themes investigated in teacher talk (Walsh, 2006; p.,141)

Features of Teacher

Description

\section{Talk}

A

Scaffolding

repair

C Content Giving feedback to the message rather the words feedback used.

D Extended Allowing sufficient time (several seconds) for Wait-time students to respond or formulate a response.

$\mathbf{E}$ Genuine questions to which the teacher does not

Referential questions

F Seeking Teacher asks a student to clarify something the student has said.

clarification teacher has said. 


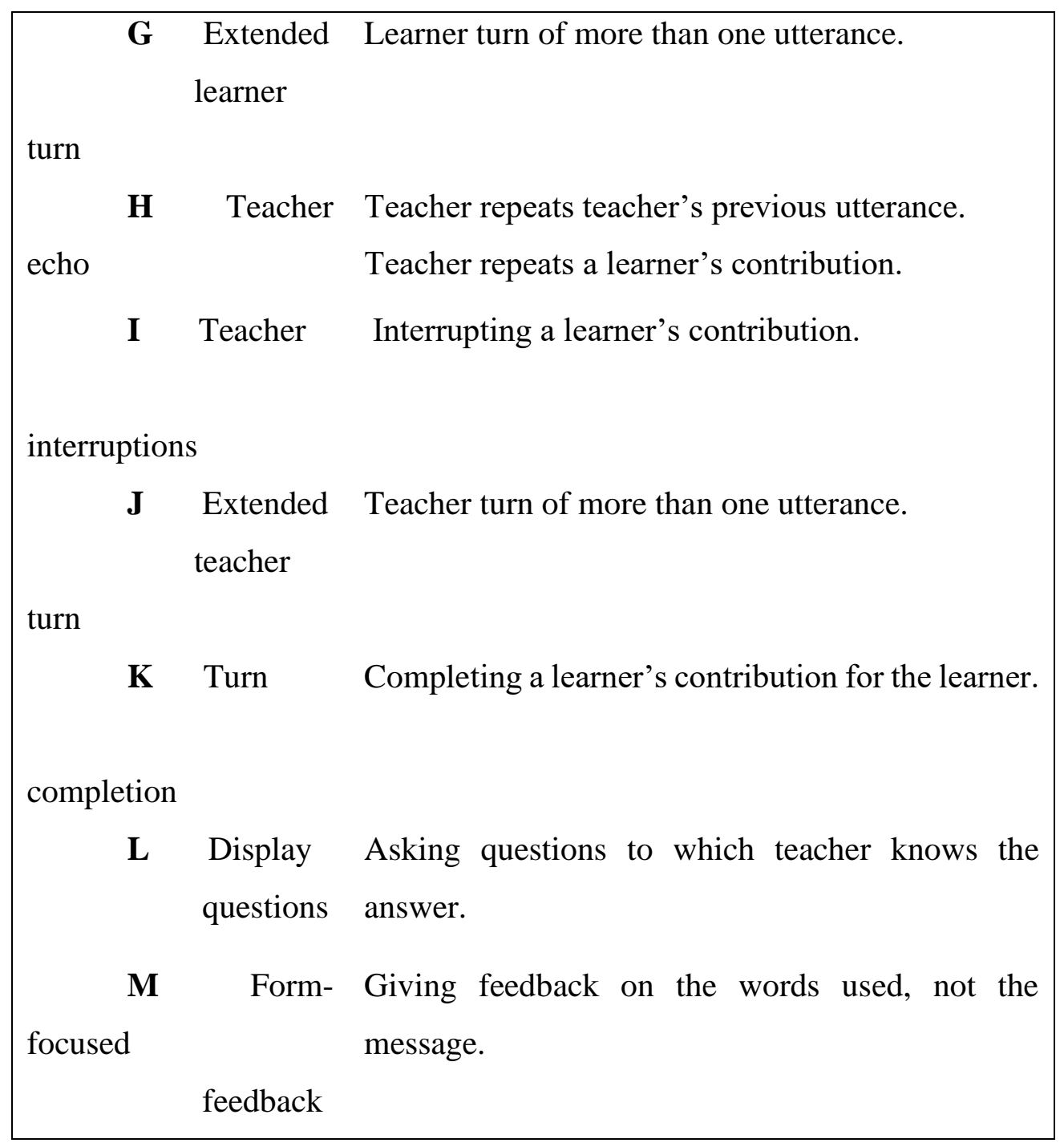

The second research question refers to the impact of teachers' experience on the quality of teacher talk with regard to communicative features. Investigating eight features of teacher talk revealed that experienced 
teachers are generally better in terms of quality of their talk. Moreover, the findings of the research suggest that these TT features should be taught to novice teachers as well as experienced teachers in pre-service teacher training program which helps teachers to improve their performance, in this regard Safir Institute had asked for the findings of this research. In order to address the second research question concerning how such distinctive communicative features could reveal the experience of teachers, this study analyzed data gained from observation sessions and recorded materials. The following subsections present the results of this study.

\section{Analysis of display questions}

Grounded on data obtained from observation and recorded materials, one can argue that both novice and experienced teachers made use of display questions in a wide range of modes or micro-contexts, particularly while checking their students' comprehension, mostly in the reading tasks.

Below is an excerpt from teacher talk in a classroom run by a novice teacher

NT1: what is the meaning of "make an effort" here?

St: I don't know

NT1: Ok, read the text again and try to guess the meaning.

An example of display question in experienced teacher talk:

ET2: what do we call people who travel a lot?

St: Travelholic? (students laugh)

ET2: (Teacher made more examples) for example Marco polo or Ibn Battuta

St: ... 
ET2: They love to travel we call them "globetrotter"

\section{St: Globetrotter?}

ET2: yes (with an enthusiastic voice) globetrotter

Both examples mentioned above were instances of display questions with the teachers knowing the answers. Yet the example provided by the experienced teacher appears to be far better in terms of quality, representing more lexical items and repetition technique. One can see the experienced one elaborated more and gave examples to get the idea across well to the students. Thus, it can be argued that this is a favorable communicative feature emerging in the talk of an experienced teacher due to her teaching experience.

\section{Analysis of referential questions}

In the analyzed data, both groups of novice and experienced teachers frequently used referential questions to ensure comprehension with their students. Below are two excerpts from novice and experienced teachers while utilizing referential questions in their talk:

Excerpt from novice teacher

NT3: What do you think you will be doing 5 years from now?

St: I think I'll be...um... I'll be working in my own company

NT3: your own company?

St: yes, my own company

Excerpt from experienced teacher

ET4: Ladies? Is there any of these singers you wish you had been to their concerts in the past?

St: Yes, yes, Amr Diab, he has a wonderful voice 
ET4: What would you have done if you had been to their concert? (then she asked them to discuss this in groups)

The underlined questions in the above excerpts indicate how referential question are represented in the case of both novice and experienced cases analyzed in this study. Whilst both teachers used referential questions, experienced teacher continued the example with group work and continued the task with learner/ learner interaction. Such feature did not exist in the case of in-experienced teachers.

Analysis of direct and indirect repair

Both groups of teachers mostly gave direct feedback on the students' pronunciation errors. Nevertheless, it was identified that some novice teachers either ignored the students' grammatical errors while speaking or corrected them on the spot. For instance, in the case of NT5 below, "very much cars" was a sentence produced by a student which the teacher corrected its mistake directly and immediately. Yet, most of the experienced teachers wrote their students' errors on a piece of paper so as not to distract them while speaking, and at the end of each session they put their students' errors on the board, indirectly corrected them with the help of the learners. Direct error correction may seem far less time-consuming and the teacher opts for a very open and direct approach to error correction as preferred by their learners. Safir Institute seemingly took an opposing view on this issue and most teachers in their classes were trying to correct errors indirectly, which based on Walsh's (2002) assumptions reduces interruption and maintains the flow.

An excerpt of a novice teacher illustrating the direct repair

St: Very much cars 
NT5: there were many cars (she interrupted the student and explained that "very" is used for adjectives and car is a noun)

An excerpt of an experienced teacher illustrating the direct repair

St: She want [sic] to went to the party

ET4: (remains silent and just takes notes, when all students finished speaking then she wrote their mistakes on the board and asked them to identify mistakes and correct them).

Negotiation of meaning through clarification request and repetition

Observations and recordings indicate that both novice and experienced teachers negotiate meanings during their instruction as a communicative feature of TT emerging in an L2 classroom micro context (Walsh, 2006a). Clarification request and repetition as a way of meaning negotiation were frequently used by both groups. Although experienced teachers sometimes moved beyond the classroom subject and discussed the students' favorite topics, including books and movies, to engage them in negotiation of meaning and interaction. This seemingly reflects the novice teachers' inclination to the content of the book rather than other subjects.

An example of repetition in a novice teacher talk:

St: All about his brave

NT4: All about his bravery?

St: yes, bravery

NT4: bravery that's it 
An example of clarification request in an experienced teacher classroom:

ET2: What is it about?

St: It's a movie

ET2: about what? (a clarification request by the teacher)

St: Music, It's musical

In the above example, ET2 asked "about what" to elicited more clarification on the part of the student thereby making a connection between the content of the book and the student's personal experience beyond the classroom context, which could lead to more learner involvement.

Experienced teachers mostly sought for clarification about subjects beyond the content of the book. In this way, they could engage students with a real communication. Otherwise, the focus of novice teachers was to a great extent on the content of the book. Nunan (1987, p. 144) highlights that "there is growing evidence that, in communicative classes, interaction, may in fact, not be very communicative after all and there is also the feeling that the only real communication between learners takes place during the break or after the class".

\section{Content and Form-Focused Feedback}

Both novice and experienced teachers participating in this study demonstrated some level of focus on the message rather than form, though it appeared that the experienced teachers' emphasis on content was more obvious. "Feedback on content involves responding to the content of what learners are saying rather than commenting solely on the form" (Haydarova, 2018). In most cases, they tried not to interrupt students for correcting their grammatical errors. In the case of grammatical problems on the part of students they solely took notes. This is consistent with what Thornbury (1996) asserted 
as regards content-focused feedback which is one of the communicative features of teacher talk.

\section{Analysis of extended wait-time}

Experienced teachers appeared to be more patient during the Q\&A tasks. After asking questions they waited for a few seconds, allowing the student to think and process in their mind. The novice teachers, on the other hand, allowed less than enough wait time. While, this was not true in the case of all observed novice teachers, most of them had this problem. One can, thus, argue that such issue may be due to their unawareness concerning the importance of this communicative feature in teacher talk. Extended wait-time by teachers can lead to more learner involvement which supports similar findings by Huan and Wang (2011). Additionally, it can increase the number of students' responses and lead to more complex answers as well as learner/learner interaction (Walsh, 2002).

An excerpt showing wait time in a novice teacher's classroom:

NT4: How do you pronounce these words? "rid" and "ride" (she wrote these 2 words on the board, then she waited only for 2 seconds and then she pronounced the correct form)

NT4: this is rid /rId/ and this is ride /raid/

An excerpt showing wait time in an experienced teacher's classroom:

ET1: what kind of play it is?

St: ...

ET1: What kind of play? Think about it... (wait time)

St: music?

ET1: uhu, musical (she waited and gave the student a second chance to think more) 
In the first example NT4 asked a question from students and waited for only 2 seconds, which was not enough for the process of thinking. Otherwise, ET1 asked a question and said "think about it" then waited for a longer time to give the student a second chance to think about the answer.

\section{Analysis of language grading:}

Based on one of the researcher's talk with the institute's supervisor, all teachers at Safir Institute passed some pre-service courses which had an emphasis on this issue; all teachers should bring their talk to the level of students, although it does not mean that they should understand each and every word. Observations revealed that in some cases novice teachers overused difficult words while speaking which means that they were not aware of how difficult their language may appear to students. This is on the same note with Stanley and Stevenson's assertion (2017) on difficulties novice English language teachers have with level adaptation to make their speech more understandable to learners. But all-in-all, the teacher educators in pre-service courses of this institute did an admirable job in highlighting language grading consistency.

Teachers' use of first language: One of the strictest house rules that applies at Safir indicates none of the students or teachers are allowed to use their first language (Persian) in the classroom. All-in-all, teachers obeyed this rule, yet in some cases teachers spoke only one Persian word to make sure comprehension occurred. Thus, there was not a significant difference between novice and experienced teachers' use of L1.

The results indicated that in terms of display and referential questions, both novice and experienced teachers used various questions in the process of 
their teaching; however, quality of display and referential questions in experienced teachers' talk was more acceptable. Their instruction through asking questions was followed by more desirable examples or group work. Indirect and direct error correction was visible in the process of giving instruction to learners by both novice and experienced teachers. Although novice teachers sometimes seem to be impatient about students' errors and corrected them on the spot; experienced ones in most cases were trying to write students' errors on a piece of paper and share them with all students at the end of conversation. Students appeared to be satisfied with indirect error correction specially in the analyzed talk relating to experienced teachers as it represented more comprehensive examples.

Asking questions by teachers is a kind of providing input (Hasan, 2006) and it is an integral part of classroom interaction (Ho, 2005). Language learners have an opportunity to participate in the classroom interaction when they are asked a question. Thus, questioning plays an important role in language acquisition (Ozcan, 2010). Also, teachers' directed questions can increase the amount of time for students to talk. According to Ozcan (2010) the most important factor within an effective EFL course is students' participation, learners need to be stimulated through questioning. Therefore, asking questions by teachers is one of the most common methods in facilitating students' involvements (Ozcan, 2010).

The focus of the present study is on display and referential questions in teacher talk, since it is an effective way which enables students to be more productive (Bozorgian \& Fallah, 2017). Moreover, Long and Sato (1983) and Van Lier (1988) emphasized that referential questions can create discourse which produce a flow of conversation from students to the teacher and may 
create a more communicative speech. Referential questions are questions which the teacher does not know the answer to them or more specifically, they do not have a particular answer and thus, they are used to create genuine communication. Additionally, these kinds of questions have a specific purpose of allowing students to express their opinions and exchange information (Ellis, 1994; Thompson,1997; Thornbury, 1996). Furthermore, Ozcan (2010) indicated that referential questions encourage more learner involvement in the classroom and the answer to such questions are not limited. Thus, students can provide longer answers, in other words, it can increase students' talk time.

Besides, negotiation of meaning through clarification request and repetition were frequently used by teachers. However, experienced teachers sometimes went beyond the classroom's main focus and discussed students' favorite topics. Novice teachers, on the other hand, appeared to be more loyal to the content of the book. Moreover, the focus of both groups of teachers was mostly on the content and message rather than form owing to the outcome of pre-service courses offered at Safir Institute.

Additionally, teachers should be aware of the relationship between their experience and the rate of professional growth through these courses which help teachers feel more confident about their own talk. At the end of practical phase of this study, one of the authors shared the results with Safir Institute and had an interview with one novice and one experienced teacher -both teachers claiming that they were neither aware of such frameworks which help them to evaluate their own talk, nor were they informed of TT significance on students' involvement.

The results of this study are in line with the findings of previous studies on teacher characteristics and language education such as Tsui (2003) 
and Akbari \& Tajik (2012) highlighting experience as an intervening fact. Additionally, such findings are quite in harmony with the observation that Rahmani Doqaruni (2017, p.17) made regarding the experienced teachers in his study who "used the least number of" communication strategies. He assumed that the difference lies, out of other possibilities mentioned, in the teacher education program.

In terms of contributions to the theory in the teacher talk research, the findings show the SETT framework used as the foundation of many studies in teacher talk need to be tailed based on the context as mentioned by previous studies (e.g. Pande, 2019). Language Grading and Teachers' Use of First Language were two elements that should be incorporated into the model for future studies on teacher talk in an EFL situation.

\section{CONCLUSION}

Research into teacher talk is of noteworthy significance in the literature on teacher education and L2 language teaching. The results of this study lead to a more profound understanding of the teacher talk function in the classroom discourse and would benefit pre-service teachers on how to use language and critique their own performance particularly through the use of SEET and the TTFS frameworks. Moreover, using these frameworks help teachers to encourage learner involvement in the classroom. As Asik and Gonen (2016) believe, the SETT framework helps teachers develop a more critical eye by evaluating their use of language. 
We are aware of this study's limitations due to investigating eight features of teacher in experienced and novice teachers based on the data obtained from cases focused in this study. As such there is a need to examine other features as well, including scaffolding, turn completion and teacher echo. Additionally, this study investigated teacher talk in ten cases recruited at Safir Institute, other institutes and schools can be the subject of study for further analysis. Other researchers need to conduct their research with a larger number of participants and in various teaching contexts.

We hope to have contributed to defining new research paths that explore the potential of communicative aspects of classroom talk in the post method era within the language teaching discipline and teacher education studies. New lines of research in classroom talk can also highlight the intersection of teacher-student interaction with pre- and in-service teacher training courses.

\section{REFERENCES}

Aisyah, N. (2016). An Analysis of Teachers 'Talk in an EFL Classroom. Journal of English and Education, 4(2), 63-79.

Akbari, R., \& Tajik, L. (2012). Second-language teachers' moral knowledge base: A comparison between experienced and less experienced, male and female practitioners. Journal of Moral Education, 41(1), 39-59.

Ary, D., Jacobs, L. C., Irvine, C. K. S., \& Walker, D. (2018). Introduction to research in education. Cengage Learning.

Aşık, A., \& Kuru Gönen, S. İ. (2016). Pre-service EFL teachers' reported perceptions of their development through SETT experience. Classroom Discourse, 7(2), 164-183.

Doganay, A., \& Ozturk, A. (2011). An Investigation of Experienced and Inexperienced Primary School Teachers' Teaching Process in Science and Technology Classes in Terms of Metacognitive 
REGISTER JOURNAL

Vol. 12, No. 2, (2019), pp.100-125

p-ISSN: 1979-8903; e-ISSN : 2503-040X

Website: http://journalregister.iainsalatiga.ac.id/index.php/register/

Strategies. Educational Sciences: Theory and Practice, 11(3), 13201325.

Ellis, R. (1985). A variable competence model of second language acquisition. IRAL, 23(1), 47-59.

Ellis, R. (2015). Understanding second language acquisition 2nd EditionOxford applied linguistics. Oxford university press.

Flanders, N. A. (1970). Analyzing teaching behavior.

Freitas, I. M., Jiménez, R., \& Mellado, V. (2004). Solving physics problems: The conceptions and practice of an experienced teacher and an inexperienced teacher. Research in Science Education, 34(1), 113-13.

Gatbonton, E. (2008). Looking beyond teachers' classroom behaviour: Novice and experienced ESL teachers' pedagogical knowledge. Language Teaching Research, 12(2), 161-182.

Haydarova, S. Z. (2018). Communicative teacher talk in the English classroom. Theoretical \& Applied Science, (10), 323-326.

Huan, F., \& Wang, L. (2011). A Self-Evaluation of Classroom Language Used When Teaching Grammar. International Education Studies, 4(4), 170174.

İnceçay, G. (2010). The role of teacher talk in young learners' language process. Procedia-Social and Behavioral Sciences, 2(2), 277-281.

Khany, R., \& Malmir, B. (2017). The Development and Validation of an English Language Teacher Talk Functional Scale. Iranian Journal of Language Teaching Research, 5(2), 37-52.

Melnick, S. A., \& Meister, D. G. (2008). A comparison of beginning and experienced teachers' concerns. Educational Research Quarterly, 31(3), 39-56.

Moskowitz, G. (1976). The classroom interaction of outstanding foreign language teachers. Foreign Language Annals, 9(2), 135-143.

Pande, M. H. (2019). Exploring self-evaluation of teacher talk (SETT) in the Indian ESL context with in-service teachers. Foretell, 38, 47-60. 
Poorebrahim, F., Talebinejad, M. R., \& Mazlum, F. (2015). Constructive or obstructive features of teacher talk in Iranian EFL classes. Theory and Practice in Language Studies, 5(4), 729-736.

Rahmani Doqaruni, V. (2017). Communication strategies in experienced vs. inexperienced teachers' talk: A sign of transformation in teacher cognition. Innovation in Language Learning and Teaching, 11(1), 1731.

Scherer, G. A., \& Wertheimer, M. (1964). A psycholinguistic experiment in foreign-language teaching. McGraw-Hill.

Sert, O. (2013). Integrating digital video analysis software into language teacher education: Insights from conversation analysis. ProcediaSocial and Behavioral Sciences, 70, 231-238.

Shamsipour, A., \& Allami, H. (2012). Teacher Talk and Learner Involvement in EFL Classroom: The Case of Iranian Setting. Theory \& Practice in Language Studies, 2(11).

Stanley, P., \& Stevenson, M. (2017). Making sense of not making sense: Novice English language teacher talk. Linguistics and Education, 38, $1-10$.

Thornbury, S. (1996). Teachers research teacher talk. ELT journal, 50(4), 279289.

Tsui, A. (2003). Understanding expertise in teaching: Case studies of second language teachers. Ernst Klett Sprachen.

Walsh, S. (2002). Construction or obstruction: Teacher talk and learner involvement in the EFL classroom. Language teaching research, 6(1), 3-23.

Walsh, S. (2003). Developing interactional awareness in the second language classroom through teacher self-evaluation. Language awareness, 12(2), 124-142.

Walsh, S. (2006a). Talking the talk of the TESOL classroom. ELT journal, 60(2), 133-141.

Walsh, S. (2006b). Investigating classroom discourse. New York: Routledge. 